\title{
Successfully Treated Riga-Fede Disease
}

\author{
Aslan Yürekli ${ }^{1}$, Didem Dinçer ${ }^{2}$
}

1 Bayburt State Hospital Dermatology Department, Bayburt, Turkey

2 Ufuk University Dermatology Department, Ankara, Turkey

Key words: Riga-Fede disease, lingual ulcer, trauma

Citation: Yürekli A, Dinçer D. Successfully treated Riga-Fede disease. Dermatol Pract Concept. 2019;9(3):218-219. DOI: https://doi. org/10.5826/dpc.0903a11

Accepted: November 21, 2018; Published: July 31, 2019

Copyright: @2019 Yürekli and Dinçer. This is an open-access article distributed under the terms of the Creative Commons Attribution License, which permits unrestricted use, distribution, and reproduction in any medium, provided the original author and source are credited.

Funding: None.

Competing interests: The authors have no conflicts of interest to disclose.

Authorship: Both authors have contributed significantly to this publication.

Corresponding author: Aslan Yürekli, MD, Bayburt State Hospital Dermatology Department, Bayburt, Turkey. Email: aslanyurekli03@ hotmail.com

\section{Introduction}

Riga-Fede disease (RFD) is a benign lingual ulceration caused by repetitive trauma. It was described initially by Riga in 1881 and by Fede in 1890 . It is usually caused by the sharp edges of newly erupted teeth. Therefore, the disease is usually seen in infants and may result in malnutrition and lack of weight gain due to the difficulty in breastfeeding the baby. RFD can also occur as a result of teething in childhood. The disease can be incorrectly diagnosed as malignancy [1]. For this reason it is important to diagnose the disease correctly, to avoid radical treatment. For treatment, destruction of the trauma source is targeted. Here we report a 9-year-old boy with chronic lingual ulceration diagnosed as RFD based on clinical features.

RFD is usually caused by recurrent dental trauma effects of natal or neonatal teeth within the first month after birth. However, it has been reported that the disease can be seen in childhood as well, just as it was in our patient. Because of its macroscopic and microscopic features, many lesions are confused with RFD. Differential diagnosis includes squamous cell carcinoma, ulcerative candidiasis, fungal and bacterial infection, primary syphilis, tuberculosis, lymphoma, sarcoma,

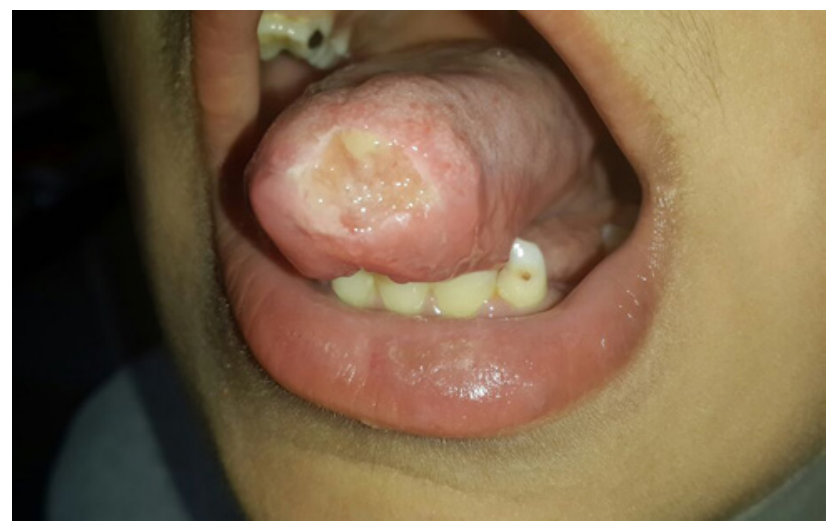

Figure 1. Chronic lingual ulceration on the ventral surface of the tongue. [Copyright: @2019 Yürekli and Dinçer.]

and agranulocytosis. Thus it is important to diagnose the disease and prescribe the correct treatment.

\section{Case Presentation}

A 9-year-old boy presented at our clinic with chronic lingual ulceration (Figure 1). The lesion was on the ventral surface of the tongue. There was no evidence of erythema or bleeding at the lesion base. He had used several treatment options such 


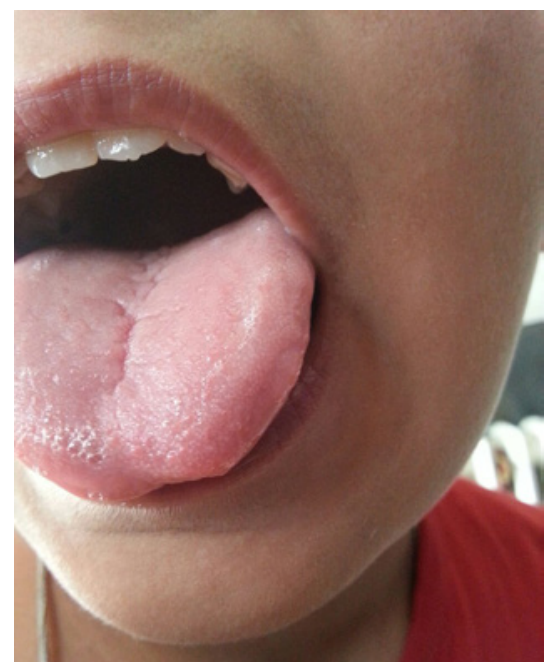

Figure 2. Lingual ulceration resolved after 6 months of treatment. [Copyright: (92019 Yürekli and Dinçer.]

as topical steroid and antiseptic mouthwashes, but there was no response to these treatments. In his oral examination the left lower canine looked quite sharp. The patient had no licking habit. Laboratory investigations such as complete blood cell count and routine biochemistry analysis were within normal values. Neurological examination did not reveal any findings. No febrile illnesses or other severe diseases were found in the medical history of the patient. The patient was diagnosed with RFD based on clinical features. Because it was thought that the sharp tooth may have been the chronic trauma source, the patient visited an oral diagnosis and treatment clinic to have the left lower canine rasped. Lingual ulceration resolved after 6 months (Figure 2).

\section{Conclusions}

RFD was defined in 1881 by Italian physician Riga. In 1890, Fede performed histological studies of this lesion and identified it as a benign and noncommon mucosal disease. It is most frequently
(60\% of cases) observed on the tongue [2]. Although oral lesions seen in RFD may be self-limited and may spontaneously recover, false or delayed diagnosis and ineffective treatment can cause long-term persistent tongue damage, malnutrition, and growth retardation.

As a result, ulcers seen in the oral mucosa may be easily confused with other malignant lesions and may lead to aggressive interventions, so a more conservative treatment may be used to avoid unnecessary radical therapies as in our case.

\section{References}

1. Li J, Zhang YY, Wang NN, Bhandari R, Liu QQ. Riga-Fede disease in a child. Clin Exp Dermatol. 2016;41(3):285-286.

2. Hong P. Riga-Fede disease: traumatic lingual ulceration in an infant. J Pediatr. 2015;167(1):204. 